\title{
LEF1 reduces tumor progression and induces myodifferentiation in a subset of rhabdomyosarcoma
}

\author{
Julia Dräger ${ }^{1, *}$, Katja Simon-Keller ${ }^{2, *}$, Tobias Pukrop ${ }^{3,4}$, Florian Klemm ${ }^{4}$, Jörg \\ Wilting $^{5}$, Carsten Sticht ${ }^{6}$, Kai Dittmann? ${ }^{7}$ Matthias Schulz ${ }^{4}$, Ivo Leuschner $^{8}$, \\ Alexander Marx ${ }^{2}$, Heidi Hahn ${ }^{1}$ \\ ${ }^{1}$ Department of Human Genetics, University Medical Center, Göttingen 37073, Germany \\ ${ }^{2}$ Institute of Pathology, University Medical Center Mannheim, Mannheim 68167, Germany \\ ${ }^{3}$ Clinic for Internal Medicine III, Hematology and Medical Oncology, University Regensburg, Regensburg 93053, Germany \\ ${ }^{4}$ Department of Hematology/Medical Oncology, University Medical Center Göttingen, Göttingen 37099, Germany \\ ${ }^{5}$ Institute of Anatomy and Cell Biology, University Medical Center Göttingen, Göttingen 37075, Germany \\ ${ }^{6}$ Center of Medical Research, Bioinformatic and Statistic, Medical Faculty Mannheim, Mannheim 68167, Germany \\ ${ }^{7}$ Institute for Cellular and Molecular Immunology, University Medical Center Göttingen, Göttingen 37073, Germany \\ ${ }^{8}$ Kiel Paediatric Tumor Registry, Department of Paediatric Pathology, University Hospital Schleswig-Holstein, Kiel 24105, Germany \\ *These authors contributed equally to this work
}

Correspondence to: Heidi Hahn, email: hhahn@gwdg.de

Keywords: RMS, LEF1/TCF, WNT/ $\beta$-catenin signaling

Received: September 26, 2016

Accepted: November 30, 2016

Published: December 10, 2016

\section{ABSTRACT}

Rhabdomyosarcoma (RMS) is the most common soft tissue sarcoma in children and show characteristics of skeletal muscle differentiation. The two major RMS subtypes in children are alveolar (ARMS) and embryonal RMS (ERMS). We demonstrate that approximately 50\% of ARMS and ERMS overexpress the LEF1/TCF transcription factor LEF1 when compared to normal skeletal muscle and that LEF1 can restrain aggressiveness especially of ARMS cells. LEF1 knockdown experiments in cell lines reveal that depending on the cellular context, LEF1 can induce pro-apoptotic signals. LEF1 can also suppress proliferation, migration and invasiveness of RMS cells both in vitro and in vivo. Furthermore, LEF1 can induce myodifferentiation of the tumor cells. This may involve regulation of other LEF1/TCF factors i.e. TCF1, whereas $\beta$-catenin activity plays a subordinate role. Together these data suggest that LEF1 rather has tumor suppressive functions and attenuates aggressiveness in a subset of RMS.

\section{INTRODUCTION}

Rhabdomyosarcoma is an aggressive form of sarcoma that in the vast majority of cases occur in children younger than 18 years. Despite being a rare cancer, it accounts for approximately $40 \%$ of all soft tissue sarcomas in children $[1,2]$. The two major subtypes in children are alveolar RMS (ARMS) and embryonal RMS (ERMS) showing different histological, genetic and clinical features. Thus, approximately $80 \%$ of ARMS show specific chromosomal translocations, which lead to the generation of PAX3-FOXO1 or PAX7-FOXO1 fusion proteins and are considered relevant in aetiology and prognosis [3]. Whereas fusion-positive ARMS are more aggressive, fusion-negative ARMS are clinically and molecularly similar to ERMS [4]. ERMS account for approximately two thirds of all RMS and are associated with a more favorable prognosis with a 5-year overall survival of approximately $73 \%$ compared to $48 \%$ for ARMS [1, 2, 5]. However, the survival rate for metastatic disease is only $40 \%$ for ERMS [6] and $10-30 \%$ for ARMS [7]. A better understanding of the molecular basis of this disease is important to improve current treatment schemes.

Activity of the canonical WNT (WNT/ $\beta$-catenin) pathway is frequently involved in the development of tumors. Examples include colorectal cancer, malignant melanoma, medulloblastoma and several other tumor types [8]. Active canonical WNT signaling is indicated by elevated levels of $\beta$-catenin in the nucleus and/or cytoplasm. In the nucleus $\beta$-catenin interacts with the 
LEF1/TCF family of genes [8]. Like other TCFs, LEF1 is a transcription factor and is the prototypical mediator of WNT responses [9]. In the presence of WNT signals, LEF1 binds to $\beta$-catenin via its $\mathrm{N}$-terminal $\beta$-cateninbinding domain and promotes context-dependent target gene transcription including $c-M Y C$ and $A X I N 2$. Conversely, in the absence of the WNT signal, LEF1 represses WNT-responsive genes. WNT signaling can also be limited by dominant-negative LEF1 isoforms. These isoforms are produced by alternative promotors and lack the $\beta$-catenin-binding domain, thus preventing $\beta$-catenin access to targets (see reviews [10-12]).

Moreover, LEF1 and the other TCF family members are also known as architectural transcription factors, bend the DNA in a specific angle and exert functions independently of $\mathrm{WNT} / \beta$-catenin signaling by e.g. interacting with cofactors such as ALY, Ets, TFE-3 and Sp1 [11]. Thus, LEF1 can promote growth of malignancies in the absence of $\beta$-catenin stabilization [13]. Moreover, LEF1 and TCF1 have intrinsic HDAC-activity, which is necessary for differentiation of $\mathrm{CD} 8^{+} \mathrm{T}$-cells [14].

Because of these context dependent effects, LEF1 can function as either an oncogene or a tumor suppressor. For example, transplantation of LEF1-transduced bone marrow leads to acute myeloid leukemia and B-precursor ALL in the mouse [15]. Conversely, LEF1 can repress the transcription of $M Y C$ and thus act as a tumor suppressor in a subset of human T-ALL cases [16].

Although canonical WNT signaling plays an important role in muscle development [3] only few data on its role in RMS have been published. This is due to initial studies that revealed lack of nuclear $\beta$-catenin and lack of mutations in important components of the signaling pathway in RMS samples [17]. More recent papers now show that activation of canonical WNT signaling induces the expression of myogenic differentiation markers and inhibits proliferation of RMS cell lines [18, 19]. These data support a tumor-suppressive role of canonical WNT signaling in RMS that additionally promotes myogenic differentiation.

We here examined the role of LEF1 in RMS. Our experiments show that LEF1 can function as a tumor suppressor in this tumor entity and suggest that LEF1 is possibly one of the major mediators of RMS differentiation.

\section{RESULTS}

\section{RMS biopsies express LEF1}

After quality control 41 ERMS and 7 fusionpositive ARMS samples arranged in a tumor microarray (TMA) were evaluable. The immunohistochemical analyses revealed that $43.1 \%$ of the RMS samples were positive for LEF1 although to a variable extend (Figure 1A, upper panel). When scoring the LEF1 positive samples (by multiplying the percentage of LEF1 positive cells by staining intensity) we found 41 , 5 and 2 RMS with a low, intermediate and high score, respectively (Figure 1A, lower left panel). No ARMS with a high LEF1 score was detected and in general the LEF1 score was higher in ERMS compared to ARMS, however without reaching significance (Figure 1A, lower middle panel). LEF1 protein was exclusively found in the nucleus. Consistent but variable overexpression of LEF1 was also seen on mRNA level in all fresh-frozen biopsies of our collection of 10 human ERMS and 10 human fusion-positive ARMS when compared to normal muscle (Figure 1A, lower right panel).

When $\beta$-catenin/CTNNB1 expression was analyzed half of the RMS samples (47.1\%) stained positive (Figure 1B, upper panel). Signals were detected in the cytoplasm with the exception of one ERMS case that also stained positive in the nucleus. Of the positive RMS, 28, 15 and 5 showed a low, intermediate or high $\beta$-catenin score, respectively (Figure 1B, lower left panel). Each $\beta$-catenin score was present in ERMS and ARMS (Figure 1B, upper panel and lower middle panel). On mRNA level all RMS expressed unequivocal high levels of this gene when compared to normal muscle (Figure 1B, lower right panel). We did not observe any correlation with LEF1/ LEF1 expression (data not shown).

Analysis of microarray-based expression data provided by Davicioni et al. [20] confirmed our findings. None of the performed comparisons between ARMS (PAX3-FOXO1) and ERMS as well as more detailed considerations between PAX3-FOXO1 translocation positive ARMS and various differentiation states of ERMS showed any significant difference between the two subtypes, nor correlation (Supplementary Table S1).

When the expression of the major downstream target of canonical WNT signaling AXIN2 was analyzed, we found that this gene was rather downregulated in RMS compared to normal skeletal muscle (Figure 1C).

In summary, approximately half of ERMS and fusion-positive ARMS samples express LEF1 and $\beta$-catenin, with however variable and unrelated intensity. Furthermore, the common absence of nuclear $\beta$-catenin and of AXIN2 expression suggests that canonical WNT signaling in general is not active in RMS. In this study, we tried to elucidate the role of LEF1, which can have functions independently of canonical WNT/ $\beta$-catenin signaling (see introduction), in RMS.

\section{Establishment of LEF1 knockdown RMS cell lines}

In order to analyze the function of LEF1 in RMS, we sought to either overexpress or delete LEF1 in LEF1 negative or LEF1 positive RMS cell lines, respectively. Since all examined cell lines expressed LEF1 (Supplementary Figure S1), the effects of a LEF1 
A
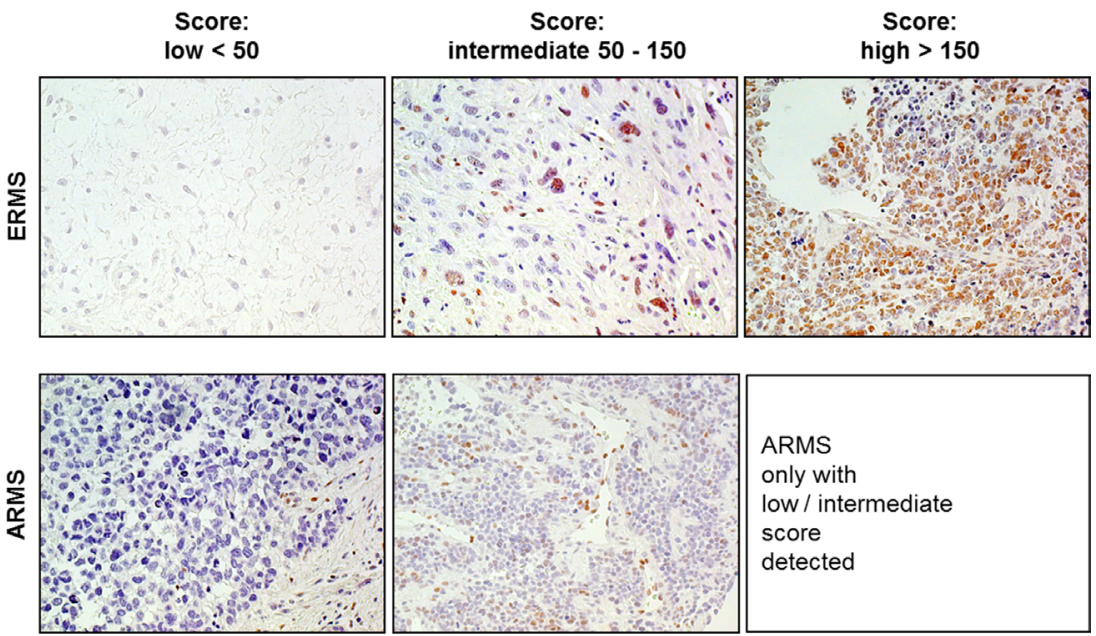

\section{ARMS}

only with

low / intermediate

score

detected
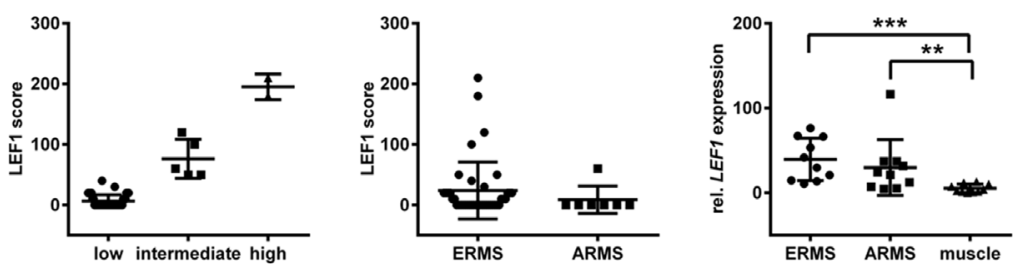

B
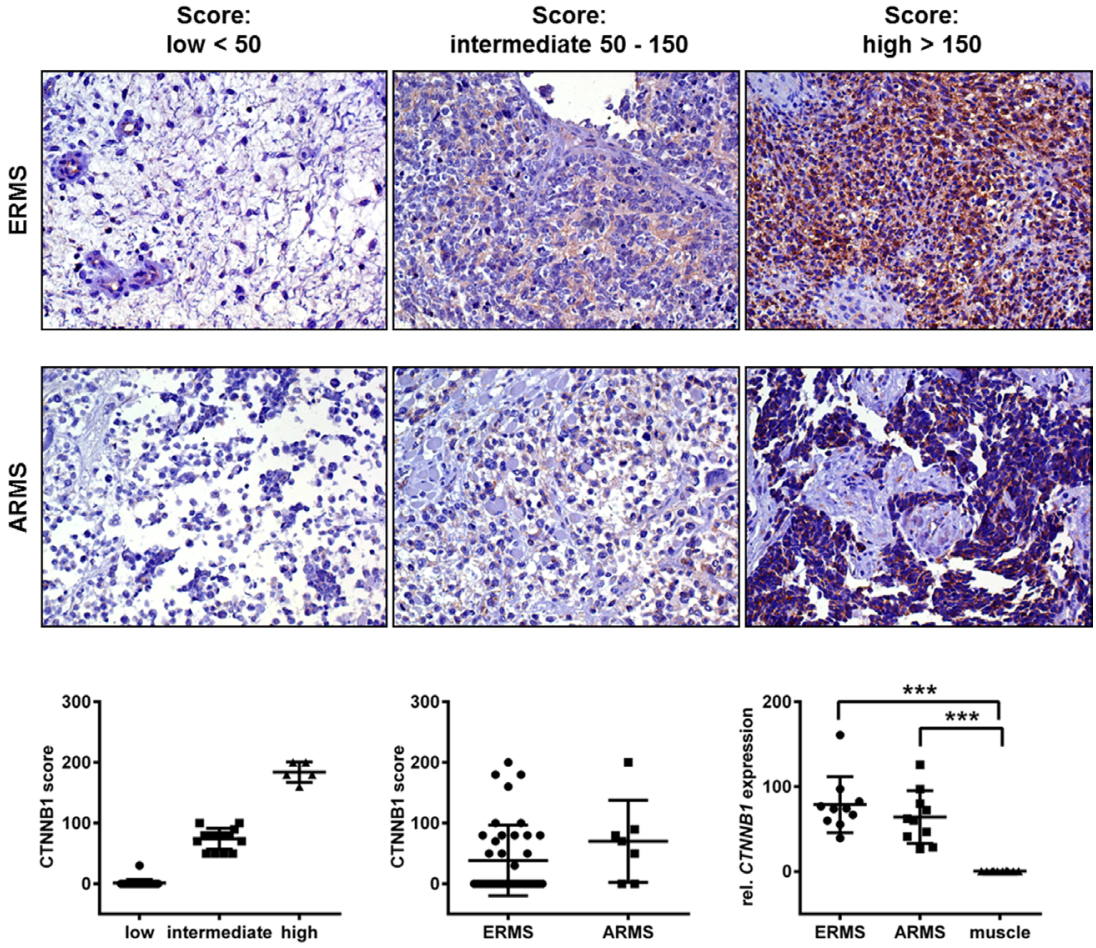

C

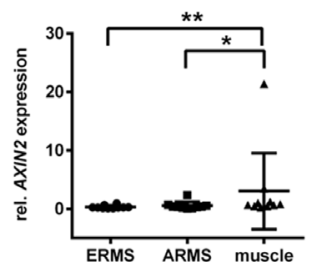


Figure 1: Immunohistochemical and/or qRT-PCR analyses of LEF1, $\beta$-catenin and AXIN2 in human ERMS and fusion-positive ARMS. Representative data for LEF1 expression is shown in (A) and for $\beta$-catenin in (B). In each case upper panel shows immunohistochemistry stainings of the respective protein (LEF1 or $\beta$-catenin) in ERMS and fusion-positive ARMS. Results were scored by multiplying the percentage of positive cells by the intensity of the staining to subdivide studied samples into low, intermediate and high expressers. Lower left and center panels show the distribution of RMS in low, intermediate and high expressers according to the aforementioned scoring system and the distribution for ERMS and ARMS, respectively; right panels show LEF1 (or CTNNB1 in B) expression levels analyzed by qRT-PCR in fresh-frozen biopsies of human ERMS $(n=10)$ and fusion-positive ARMS $(n=10)$ compared to normal muscle $(n=10)$. (C) shows qRT-PCR analysis of AXIN2 in the same biopsies. (A, B and C) Bars, $95 \%$ confidence intervals and mean values; $* * * P<0.001, * * P<0.01, * P<0.05$ by Mann-Whitney $t$-test.

knockdown (LEF1 KD) in the ERMS cell line TE671 and the ARMS cell lines Rh41 and RMS-13 were studied. Since these RMS cell lines express the full-length LEF1 isoform of $44 \mathrm{kDa}$, whereas the truncated isoform lacking the $\beta$-catenin binding site $(31 \mathrm{kDa}$ and $23 \mathrm{kDa}$; see $[9,21]$ ) were barely detected (Figure 2A), we conclude that these cell lines express functional LEF1 that can interact with $\beta$-catenin. In addition, all cell lines express the downstream targets of canonical WNT signaling, AXIN2 and $c-M Y C$ (Supplementary Figure S2). A stable LEF1 $\mathrm{KD}$ in the cell lines (Figure 2A) resulted in a significant downregulation of the LEF1 target AXIN2 only in RMS13 LEF1 KD cells (Figure 2B). Interestingly, the LEF1 target $c-M Y C$ was significantly increased in RMS-13 LEF1 $\mathrm{KD}$ and Rh41 LEF1 KD cells (Figure 2B). This is similar to T-cell acute lymphoblastic leukemia, in which LEF1inactivated cases show increased levels of $M Y C$ expression when compared with cases with intact LEF1 [16]. No significant effects of the LEF1 KD on the expression of the two mentioned genes were seen in TE671 cells.

\section{LEF1 plays a subsidiary role for canonical WNT signaling activity in RMS}

We next investigated whether LEF1 is important for the maintenance of canonical WNT signaling activity in RMS cells.

First, we transfected RMS LEF1 KD and respective control cells with the SuperTOPFlash (TOP) plasmid containing multiple TCF/LEF-binding sites or its negative control vector SuperFOPFlash (FOP) along with Renilla reporter plasmid for normalization. In order to activate canonical WNT/ $\beta$-catenin signaling, the cells were incubated with Wnt3a containing medium (Wnt3a CM). All other cells were maintained in control conditioned medium (control CM). Co-transfection with the $\mathrm{pCl}$-neo- $\beta$-catS33Y plasmid expressing a stabilized and active $\beta$-catenin ( $\beta$-catS33Y) served as a positive control (please note that control experiments employing SuperFOPFlash are shown in Supplementary Figure S3). As shown in Figure 3A, all cell lines significantly upregulated AXIN2 mRNA levels in response to Wnt3a CM (48 h incubation; Figure 3A). However, the TOP reporter was not significantly activated by Wnt3a in the ARMS cell lines Rh41 and RMS-13 irrespective of the LEF1 deletion (Figure 3B), although transfection with activated $\beta$-catenin $(\beta$-catS33Y) revealed strong luciferase induction except in RMS-13 LEF1 KD cells (Figure 3B). In contrast, the ERMS cell line TE671 was responsive to Wnt3a CM treatment and showed a more than 10-fold TOP induction (Figure 3B). Because the induction was of similar magnitude in both TE671 control and TE671 LEF1 KD cells (see Supplementary Figure S4) the data indicate that LEF 1 is not necessary for activation of the TOP reporter, i.e. it is dispensable for canonical WNT/ $\beta$ catenin-dependent signaling.

In ARMS cell lines AXIN2 expression was induced by Wnt3a despite lack of TOP reporter activity. Thus, the expression of AXIN2 must be regulated by other factors than $\beta$-catenin, e.g. by E2F1 [22]. The lack of TOP reporter activity in ARMS cells also suggests that the parental RMS-13 and Rh41 cells may i) have a mutation in the endogenous $\beta$-catenin that prevents induction of Wnt3amediated signaling activity or ii) possess a mechanism that prevents endogenous $\beta$-catenin from binding to the reporter plasmid e.g. it is possible that $\beta$-catenin is retained in the plasma membrane or cytoplasm (for review see [23]). Finally, the fact that $\beta$-catS33Y did not induce signaling activity in RMS-13 LEF1 KD cells additionally argued for a factor that prevents $\beta$-catS33Y from binding to the TCF-binding site of the reporter plasmid after LEF1 depletion.

To answer these questions, we first sequenced the $\beta$-catenin coding region (see Supplementary Table S3 for sequencing primers). Because $\beta$-catenin in the analyzed cell lines was not mutated (data not shown), we next analyzed whether $\beta$-catenin was able to translocate to the nucleus after stimulation with Wnt3a. Immunofluorescent staining demonstrated predominant nuclear accumulation of $\beta$-catenin in the ERMS cell line TE671 (Supplementary Figure S5). In contrast, nuclear $\beta$-catenin was never detected in RMS-13 cells, whereas a very weak but distinct nuclear $\beta$-catenin staining was detected after incubation with Wnt3a CM in approximately $10 \% \mathrm{Rh} 41$ cells. This is similar to the results of the TOP/FOP reporter assay that showed a 1.3-fold and 1.7-fold induction of TOP activity in RMS-13 and Rh41 control cells after Wnt3a treatment, respectively ( $P=0.58$ and $P=0.085$; see Figure $3 \mathrm{~A}$ ). Thus, these results are in favor of the hypothesis that endogenous $\beta$-catenin in Rh41 and RMS-13 is rather hold back in the plasma membrane or cytoplasm.

Finally, we examined the expression of other LEF1/ TCF factors that also interact with $\beta$-catenin and generally can activate (TCF1 and TCF4) or inhibit (TCF3 and 
TCF4) canonical WNT signaling [24, 25]. All cell lines expressed TCF1, 3 and 4, however to a variable extend (Supplementary Figure S6). When the influence of the LEF1 KD on the expression of the TCFs was examined, we found that all factors were significantly upregulated in Rh41 LEF1 KD cells, whereas all 3 factors were downregulated in RMS-13 LEF1 KD (Figure 3C). In TE671 cells, we did not find any significant changes. Together, these data suggest that the lack of TOP activation in $\beta$-catS33Y-transfected RMS-13 LEF1 KD cells may be due to extreme downregulation of all TCFs upon LEF1 depletion. However, this speculation remains to be verified in the future.

\section{LEF1 can antagonize aggressiveness of RMS}

Next, the RMS LEF1 KD cell lines were analyzed with respect to proliferation, apoptosis and their migratory and invasive properties. As shown in Figure 4A, the LEF1 $\mathrm{KD}$ increased the proliferative capacity of all three cell lines. Compared to the control-transduced cell lines the difference was significant for Rh41 LEF1 KD and RMS-
13 LEF1 KD. In the latter cell line we also observed a significant decrease in the number of apoptotic cells and a significant increase in the number of cells that migrated through the membrane insert or invaded the Matrigel in the Boyden chamber invasion assay (Figure 4A). In contrast to RMS-13, the LEF1 KD in Rh41 cells resulted in a significant decrease of the invasive capacity when compared to control cells. In TE671 cells, the LEF1 KD led to a significant increase of cell invasiveness.

Despite the fact that i) the response of the used RMS cell lines to the LEF1 KD is heterogeneous and ii) the LEF1 KD decreases the invasive capacity of Rh41 cells, the data show that LEF1 depletion generally results in increased RMS proliferation and can increase the migratory/invasive properties of RMS cells. It also can inhibit apoptosis. In summary, the presence of LEF1 can attenuate the aggressiveness of RMS cell lines. This was confirmed in vivo using the chicken CAM model, which is an established assay method for tumor growth and invasiveness. To this end, RMS-13 control and RMS13 LEF KD cells were seeded on the CAM of chicken embryos and were allowed to form tumors until day 7 . In

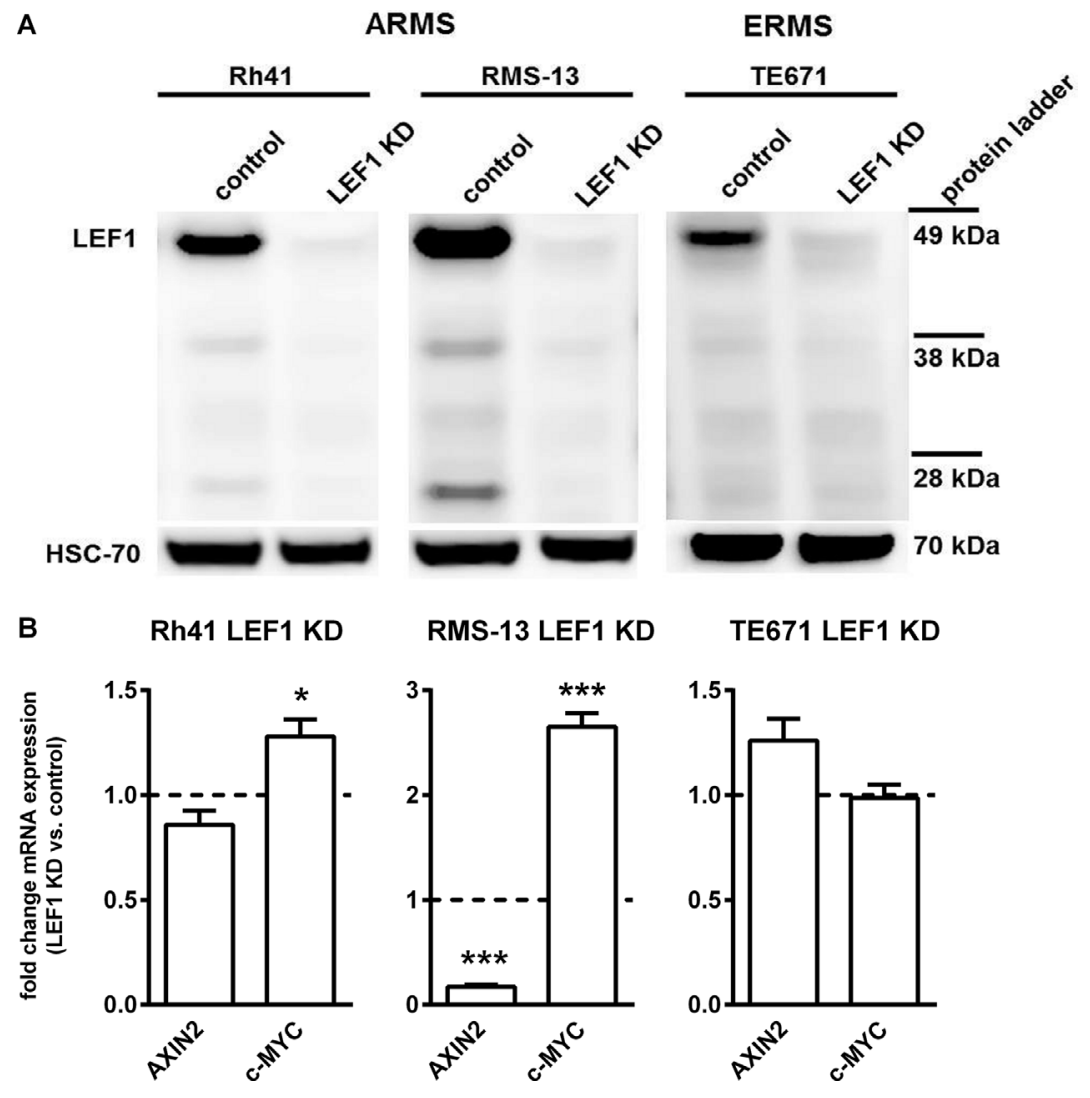

Figure 2: Generation of stable LEF1 knockdown (LEF1 KD) RMS cell lines and expression analysis of WNT target genes. (A) Representative LEF1 Western blot of human ARMS cell lines Rh41 and RMS-13 and the human ERMS cell line TE671 stably expressing a LEF1 shRNA (LEF1 KD) or empty vector control (control). HSC-70 served as loading control. Protein ladder is shown for estimation of protein size. (B) Expression of $A X I N 2$ and c-MYC in Rh41 LEF1 KD, RMS-13 LEF1 KD and TE671 LEF1 KD are shown as fold expression to the respective control cells that were set to 1 (dashed line). Gene expression levels were normalized to $18 S$ rRNA expression levels. Data represent mean + SEM of at least three independent experiments performed in duplicates and measured in triplicates; $* P<0.05, * * * P<0.001$ by Students $t$-test. 
agreement with the in vitro experiments, the LEF1 KD in RMS- 13 cells augmented tumor growth. Thus, 3 days after inoculation, the LEF1 KD cells have formed larger tumors in comparison to the control (Figure 4B). 7 days after inoculation, the LEF1 KD tumors showed hemorrhage, which was never observed in the controls (Figure 4C). Additionally, HLA immunofluorescence staining detected human MHC-identified RMS-13 LEF1 KD cells in the stroma of the CAM (Figure 4D), confirming that the LEF1 $\mathrm{KD}$ increased the migratory and invasive properties of RMS-13 cells.

\section{LEF1 can contribute to myogenic differentiation in RMS}

Since promotion of myodifferentiation can be tumor suppressive in RMS development [26], we also investigated whether LEF1 is involved in muscle differentiation processes. Indeed, in RMS-13 cells, LEF1 depletion was accompanied by an almost complete transcriptional suppression of the differentiation markers MYOD, MYOGENIN, MYH1, DESMIN and CKM (Figure 5A). This was different in Rh41 and TE671 cells, in which the LEF1 KD significantly increased $M Y H 1$ and decreased MYOGENIN mRNA level, respectively, but did not result in other significant changes (Figure 5A). Together, these data demonstrate that in dependency on the cellular context, LEF1 can induce myodifferentiation in RMS.

Since recent papers proposed a very important role of $\beta$-catenin in myogenic differentiation of RMS cells $[18,19]$, we finally investigated if $\beta$-catenin was essential for the role of LEF1 in myodifferentiation. For this purpose, all cell lines were transiently transfected with CTNNB1 specific siRNA. The successful knockdown was verified by qRT-PCR and Western Blot (see Supplementary Figure S7). Except a significant up- or downregulation of DESMIN or MYH1 and MYOGENIN, respectively, in Rh41 LEF1 KD cells (Figure 5B), the CTNNB1 KD itself did not change the expression of muscle markers. Together these data suggest that LEF1 is one of the main regulators of myodifferentiation in RMS and that $\beta$-catenin plays an inferior role in this process.

\section{DISCUSSION}

We here show that both ERMS and ARMS can express LEF1. Despite high heterogeneity among patient samples and cell lines, our LEF1 knockdown experiments using Rh41, RMS-13 (ARMS) and TE671 (ERMS) cell lines demonstrate that LEF1 can reduce tumor progression and induce myodifferentiation.

LEF1 is an important interaction partner of activated $\beta$-catenin in the nucleus. In addition, it can be a downstream target of $\beta$-catenin (see introduction and [11]). However, nuclear $\beta$-catenin signals were detected in only one ERMS sample of the TMA, which is in line with previously published data [19]. The general absence of nuclear $\beta$-catenin in RMS tissue may also explain i) the low levels of the widely recognized target of WNT/ $\beta$ catenin signaling AXIN2 in clinical samples (see Figure $1 C)$ and ii) the lack of correlation between $\beta$-catenin/ $C T N N B 1$ and LEF $1 / L E F 1$ expression levels. It also may indicate that $\mathrm{WNT} / \beta$-catenin signaling is inactive in most RMS. Indeed, our cell culture experiments using Wnt3a suggest that activation of WNT/ $\beta$-catenin signaling is only possible in subsets of RMS, such as ERMS subtypes. In addition, the fact that $A X I N 2$ activation was not seen in primary samples but in all cell lines after treatment with Wnt3a argues for a subordinate role of this WNT ligand in the primary samples.

Overexpression of LEF1 has been detected in many tumor entities. Although LEF1 frequently acts as an oncogene (for review see [27]), it also can function as a tumor suppressor gene [16]. In RMS cells, LEF1 apparently mainly acts as a suppressor. Thus, LEF1 generally attenuates proliferation of RMS cell lines, which was significant for the ARMS cell lines RMS-13 and Rh41. Furthermore, LEF1 antagonizes invasiveness of RMS-13 and TE671 that goes along with inhibition of migration and induction of apoptosis in RMS- 13 cells. It apparently can also trigger apoptotic processes in RMS13 cells (Figure 4A), as has been described for colorectal cancer [28]. This suggests that LEF1 can counteract the aggressiveness of RMS. However, the fact that LEF1 fosters invasiveness of Rh41 cells indicates that this tumor suppressive function may be restrained to specific RMS subgroups.

The anti-proliferative effect of LEF1 in RMS may be related to attenuation of c-MYC expression. Thus, the LEF1 KD in the ARMS cell lines Rh41 and RMS-13 results in significant upregulation of $c-M Y C$ expression and cellular proliferation. This is similar to T-ALL, in which LEF1 inactivation increases expression of $M Y C$ and MYC targets [16]. Because c-MYC drives proliferation of many tumor cells including RMS [29, 30], it is tempting to speculate that the increased $c-M Y C$ levels in ARMS LEF1 $\mathrm{KD}$ cells are responsible for induction of proliferation.

Furthermore, it is possible that TCF1, TCF3 and TCF4 are associated with the LEF1-mediated RMS phenotype. This is first illustrated by the effects of the LEF1 KD on invasiveness. While LEF1 KD in RMS-13 induces invasiveness, the opposite is the case for $\mathrm{Rh} 41$ cells where invasion is reduced. This was accompanied by a down- or upregulation of all TCFs, respectively. In TE671, neither TCF levels nor invasive capacity were affected (Figures 3C and 4A). This indicates that the dosage and/or composition of LEF1/TCFs factors may regulate the invasiveness of RMS cells.

Secondly, downregulation of all TCFs in RMS-13 cells upon $L E F 1$ deletion could also explain downregulation of AXIN2, which was not seen in the other cell lines. 

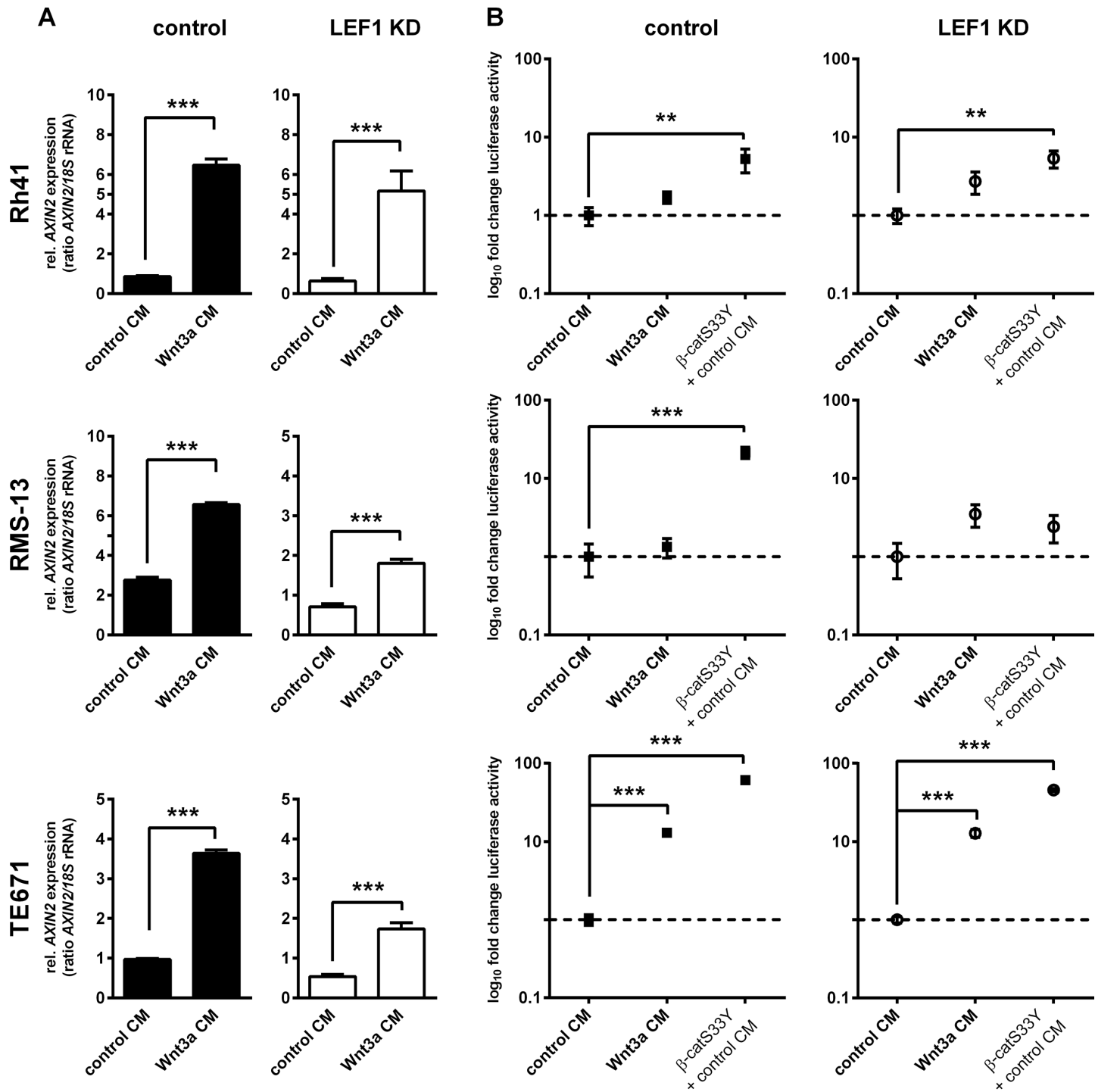

C

Rh41 LEF1 KD

RMS-13 LEF1 KD

TE671 LEF1 KD
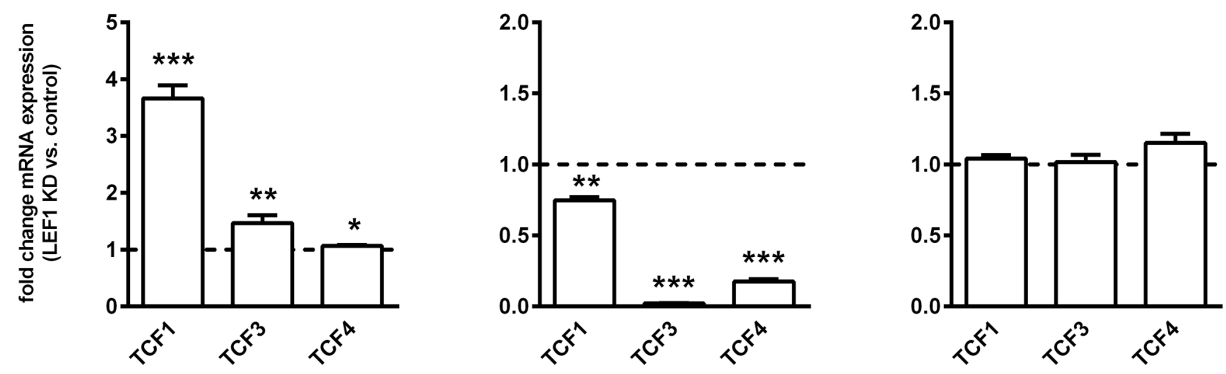

Figure 3: LEF1-dependent modulation of canonical WNT signaling activity in RMS cell lines. (A) Expression of $A X I N 2$ in Rh41 LEF1 KD, RMS-13 LEF1 KD and TE671 LEF1 KD and respective control cells in response to Wnt3a conditioned medium (Wnt3a $\mathrm{CM}$ ) or control medium (control CM). Gene expression levels were normalized to $18 S$ rRNA expression levels. Data represent mean+SEM of at least two independent experiments performed in duplicates and measured in triplicates. (B) To analyze $\beta$-catenin-dependent WNT signaling in response to LEF1 KD, cells were transfected with SuperTOPFlash (TOP) containing multiple TCF/LEF-binding sites and Renilla reporter plasmid for normalization. Luciferase activity was measured 5 days after transfection in response to Wnt3a or control CM. Transfection of the cells with pCl-neo- $\beta$-catS33Y ( $\beta$-catS33Y) served as positive control. Data show the $95 \%$ confidence intervals of at least two independent experiments performed in duplicates and are depicted as fold luciferase activity to cells treated with control CM (set to 1; dashed line). (C) Expression of TCF1, 3 and 4 in Rh41 LEF1 KD, RMS-13 LEF1 KD and TE671 LEF1 KD are shown as fold expression to the respective control cells that were set to 1 (dashed line). Gene expression levels were normalized to GAPDH expression levels. Data represent mean + SEM of at least four independent experiments measured in triplicates. (A, B and C) $* P<0.05,{ }^{* *} P<0.01, * * * P<0.001$ by Students $t$-test. 
Thirdly, TCFs may also play a role in myogenic differentiation (and thus aggressiveness) modulated by LEF1, at least in ARMS cell lines. Normal myogenic differentiation leads to the formation of myotubes. Neoplastic differentiation in RMS mostly follows the same pathway, but with less efficient tube formation and the overall proliferative and tumorigenic capacity of rhabdomyosarcoma is inversely related to the degree of myogenic differentiation [5, 31, 32]. Indeed, in RMS-13 cells LEF1 is necessary for the induction of both early (MYOD) and late (MYOGENIN, MYH1, DESMIN and CKM; [33]) muscle differentiation markers (see Figure 5A). Also in TE671 cells it is necessary for MYOGENIN expression. In contrast in Rh41 cells, LEF1 apparently suppresses the late marker $M Y H 1$, whereas the expression of other markers is not influenced. In principle, late differentiation markers like MYH1 are induced after cell cycle arrest [34]. However, the increase in BrdU incorporation in Rh41 LEF1 KD cells (see Figure $3 \mathrm{~A}$ ) strongly argues against this scenario. In addition, our setting rather implicates a $\beta$-catenin-independent, LEF1-mediated regulation of myodifferentiation. Indeed, $\beta$-catenin-independent LEF1 functions are well known and examples encompass interaction with ATF2 factors [13] and with the intracellular domain of Notch [35]. Finally, LEF1 together with TCF1 has intrinsic HDAC activity that recently was shown to repress genes counteracting cellular differentiation in specific contexts [14]. In our settings, LEF1 induces the expression of TCF1 and of muscle lineage markers in RMS- 13 cells. This is different in Rh41 cells, in which LEF1 rather suppresses TCF1 and myogenic differentiation. Therefore it is tempting to speculate that there are subgroups of RMS, in which differentiation (and concomitantly aggressiveness) is epigenetically regulated by LEF1 and TCF1. Indeed, a recent study divides RMS into 4 molecular subtypes based on their genetic and epigenetic signature [36]. Whether these speculations are true or not remains to be established in the future.

Regarding myogenic differentiation of RMS cell lines our data contrasts with recent studies implicating $\beta$-catenin-driven canonical WNT signaling in myogenic differentiation of the alveolar RMS cell lines Rh4 and Rh30 and the embryonal lines RD and RD18 [19]. RMS13 is sometimes thought to be related to Rh30 and perhaps derived from the same patient tumor. The same applies to Rh41 and Rh4 [37]. Nevertheless, the origin of RMS-13 and $\mathrm{Rh} 30$ is not clear, and $\mathrm{Rh} 41$ and $\mathrm{Rh} 4$ were developed in two different laboratories [37]. Therefore, the differences between the studies may reflect heterogeneity of different RMS cell clones. However, it is also possible that the observed differences between the cell lines depend on the histology of the individual tumor part that has been used for establishment of the individual cell line. Regardless of whether these assumptions are correct, our data indicate that the recently proposed new treatment option for RMS using GSK3 inhibitors to activate $\beta$-catenin-driven WNT signaling [38] may be only of benefit for specific subtypes of RMS, but not for others in which this pathway does not play a role.

\section{MATERIALS AND METHODS}

\section{Biopsies}

A tumor microarray (TMA) with 125 RMS biopsies from the Pediatric Tumor Register, Kiel, Germany and 20 RNA samples from the CWS ("Cooperative Weichteilsarkom Studiengruppe") tissue bank, Stuttgart, Germany (S1-S20) were studied. Histopathology of all cases was centrally reviewed by Prof. I. Leuschner (Pediatric Tumor Registry, Kiel, Germany). All patients were treated according to CWS protocols. All studies were approved by the appropriate ethics and review committees. Written informed consent according to the Declaration of Helsinki was obtained from all patients or their legal guardians, depending on the patients' age.

\section{Microarray analysis}

Expression of LEF1 and CTNNB1 was also evaluated in a publicly available RMS microarray data set [20] (available at ftp://caftpd.nci.nih.gov/pub/caARRAY/ experiments/caArray_trich-00099/,). A Custom CDF Version 20 with ENTREZ based gene definitions was used to annotate the arrays. The Raw fluorescence intensity values were normalized applying quantile normalization and RMS background correction. An ANOVA was performed to identify differential expressed genes using a commercial software package SAS JMP10 Genomics, version 6, from SAS (SAS Institute, Cary, NC, USA). A false positive rate of $\mathrm{a}=0.05$ with FDR correction was taken as the level of significance.

\section{Immunohistochemistry}

The TMA, consisting of 25 ARMS (22 fusionpositive, 3 fusion-negative) and 100 ERMS samples, were sectioned at $5 \mu \mathrm{m}$ for histological analyses. Hematoxylin eosin (H\&E) staining was performed by standard methods. The paraffin sections were stained using a rabbit monoclonal anti-LEF1 antibody (clone EPR2029Y, 1:250, pH 9.0 from Abgent; detects the $44 \mathrm{kDa}$ full-length and the $31 \mathrm{kDa}$ and $23 \mathrm{kDa}$ isoforms) and a mouse monoclonal anti- $\beta$-catenin antibody (clone 5H10, 1:200, pH 6.0 from Zymed). Immunohistochemistry was performed as described in detail elsewhere [39] using the following chemicals and reagents: antigen retrieval in Novocastra antigen retrieval solution pH 6.0 or pH 9.0 (Leica, Wetzlar, Germany); blocking of endogenous peroxidase (DAKO blocking solution, DAKO) and detection of bound antibodies 
by the immunoperoxidase/DAB-based DAKO REAL detection system (DAKO).

The proportion of LEF1- and $\beta$-catenin-positive cells as well as the intensity of the staining was estimated by a pathologist (weak staining 1 ; moderate staining 2 , strong staining 3 ). Results were scored by multiplying the percentage of positive cells by the intensity [40].

Immunofluorescence staining of cryosections (CAM assay) was performed after incubation for $1 \mathrm{~h}$ with blocking reagent (PBS, 1\% BSA). Sections were incubated overnight (ON) with an anti-HLA-A,B,C antibody followed by staining for $1 \mathrm{~h}$ with secondary Alexa Fluor 594-labeled antibody diluted in antibody solution mixed with DAPI $(1: 10,000)$. After every step specimens were rinsed twice with PBS. Samples were mounted with Fluoromount-G (Sigma-Aldrich Chemistry $\mathrm{GmbH}$ ) and dried $\mathrm{ON}$ at room temperature (RT). Stained specimens were studied with Zeiss Axio Imager.Z1 (Carl Zeiss Goettingen) and filter sets 38HE, 43 and 49. Used primary antibodies and corresponding secondary antibodies are shown in Supplementary Table S2.

For immunofluorescence staining cells were grown on slides and were fixed with $2 \%$ paraformaldehyde followed by methanol at RT for $10 \mathrm{~min}$ or $-20^{\circ} \mathrm{C}$ for 5 min, respectively. After washing with PBS, cells were
A

Rh41
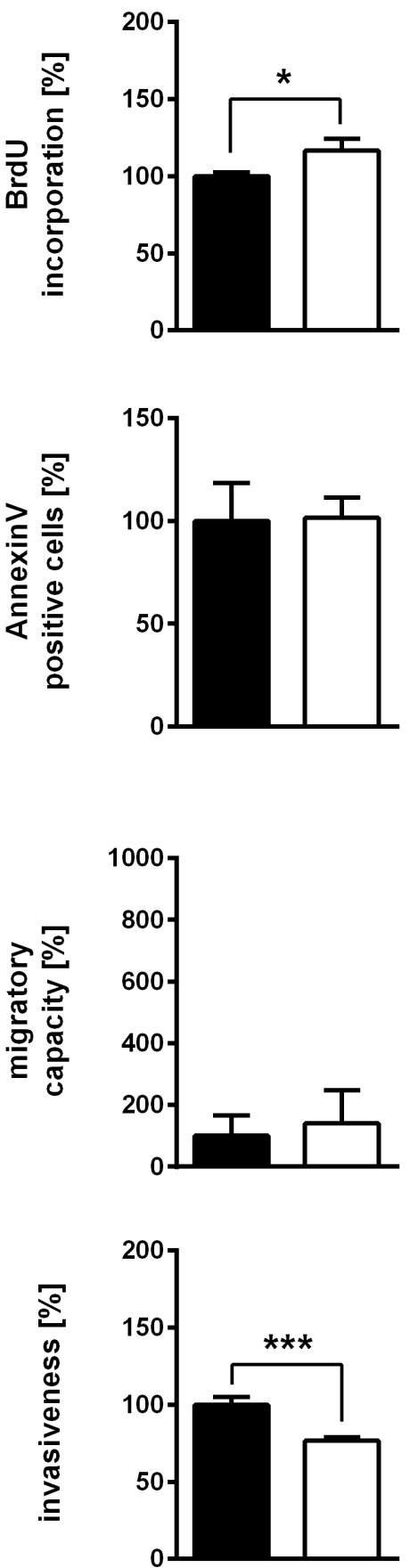

RMS-13
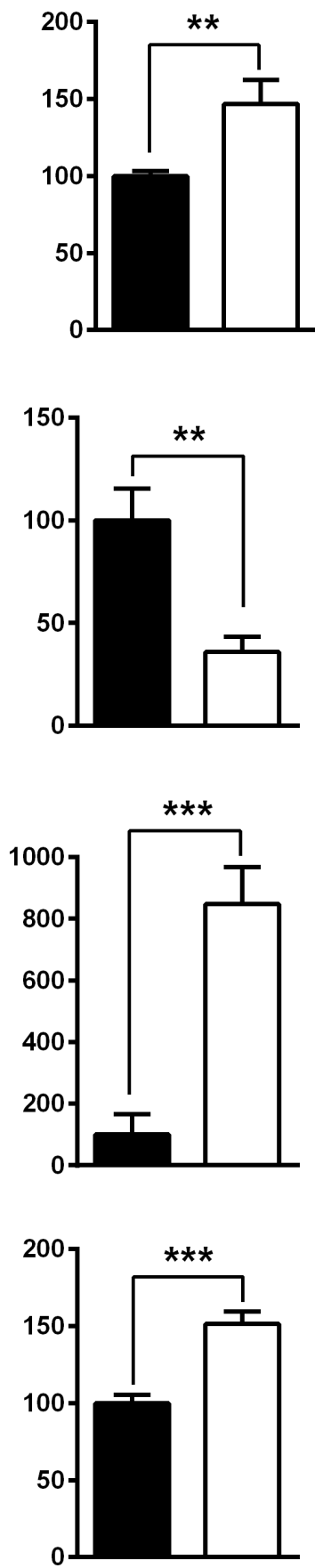

TE671
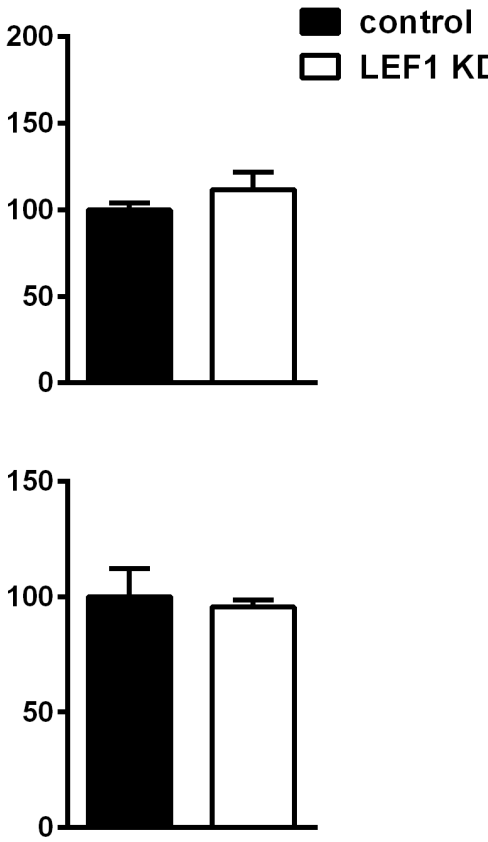

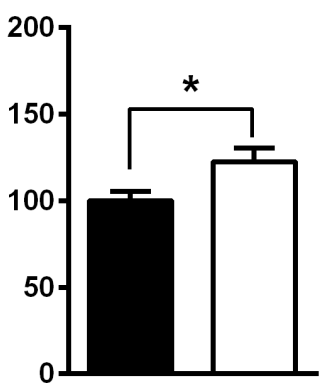



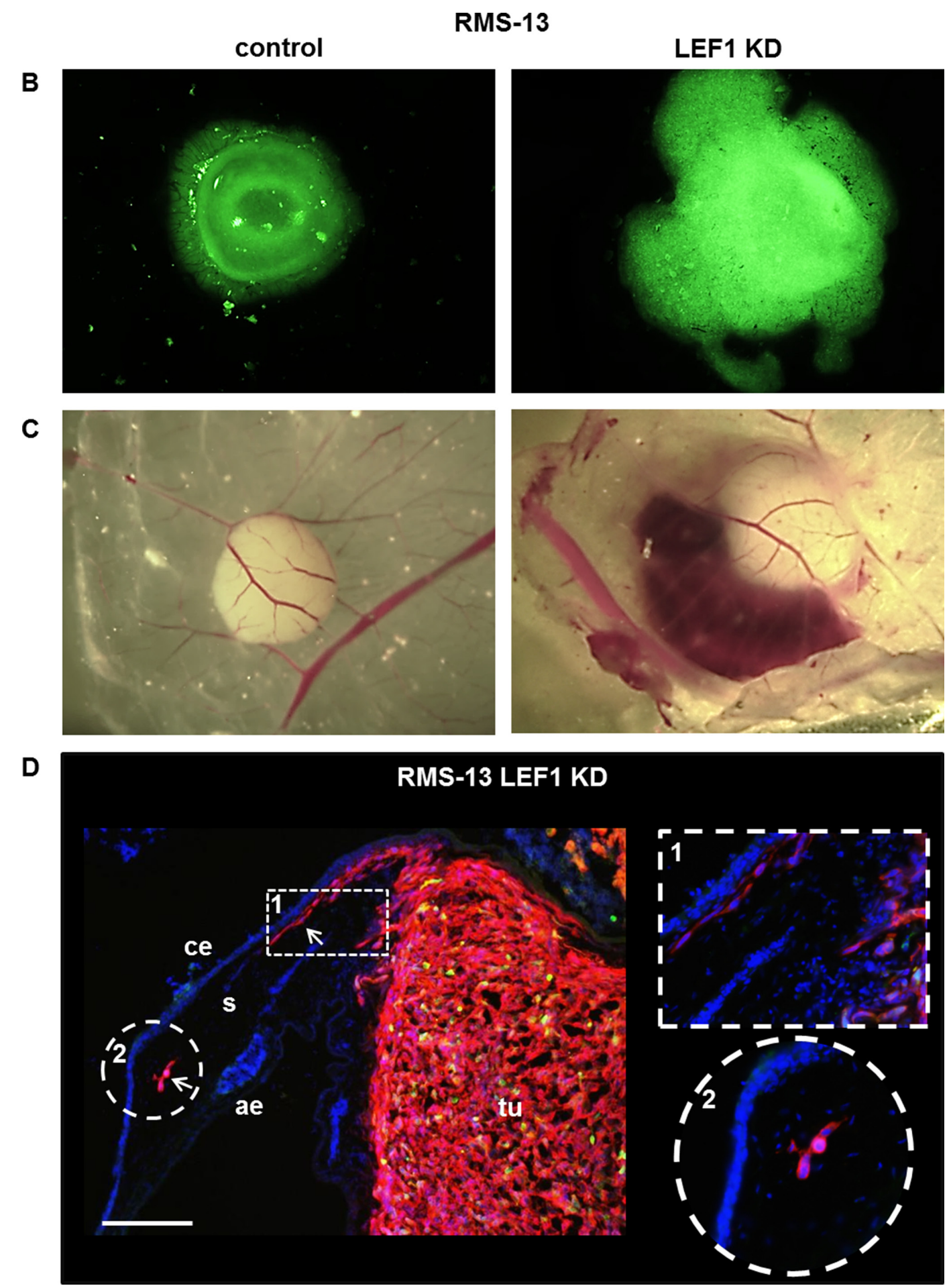

Figure 4: LEF1-dependent regulation of proliferation, apoptosis, migration and invasiveness of RMS cell lines. (A) Proliferation, apoptosis, migratory capacity and invasiveness of the cells were analyzed by BrdU incorporation assay, FACS, trans-well migration and Boyden chamber assay, respectively. Data represent mean+SEM of at least two independent experiments performed in triplicates (BrdU incorporation assay, migration assay for RMS-13) or duplicates (apoptosis, migration and invasion assay). For all measurements the respective values from control cell lines were set to $100 \%$. Comparisons were made with Students $t$-test; $* P<0.05$, ${ }^{* *} P<0.01,{ }^{* * *} P<0.001$. (B and $\mathbf{C}$ ) shows a representative intravital imaging of RMS-13 LEF1 KD and control cells in the CAM model at day 3 and 7 in each cohort post inoculation, respectively. (B) Due to stable transduction with lentiviral pGIPZ vector that expresses GFP the growth of the cells could be visualized by fluorescence (20-fold magnification). (C) RMS-13 LEF1 KD tumor growth is accompanied by destruction of vessels and hemorrhage (10-fold magnification). (D) Immunofluorescence staining of cryosection of tumors derived from RMS-13 LEF1 KD cells with anti-HLA-A,B,C (red) and DAPI (blue). White arrows mark tumor cells invading the stroma (s), and are also shown in the insets. Depicted are the chorion epithelium (ce), the allantoic epithelium (ae) and the tumor (tu). Scale bar $70 \mu \mathrm{m}$. 

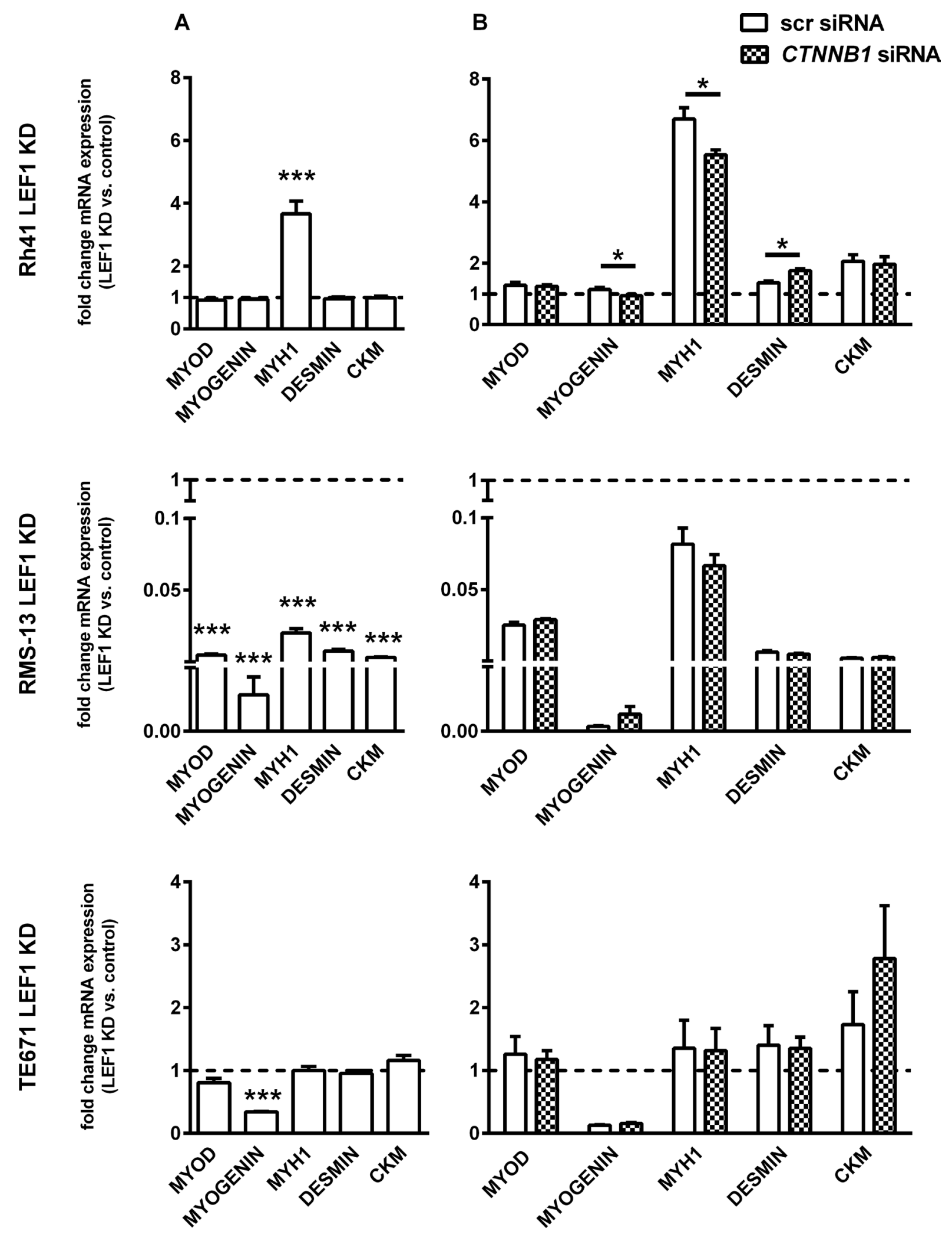

Figure 5: LEF1-dependent expression of muscle differentiation markers in RMS cell lines. (A) Expression of $M Y O D$, MYOGENIN, MYH1, DESMIN and CKM in Rh41 LEF1 KD, RMS-13 LEF1 KD and TE671 LEF1 KD are shown as fold expression to the respective control cells that were set to 1 (dashed line). (B) Expression of the same markers in the same cells after transfection with scrambled siRNA (scr siRNA) or CTNNB1 siRNA. Significances are shown for values after transfection with scr siRNA versus CTNNB1 siRNA. (A and B) Gene expression levels were normalized to $18 S$ rRNA expression levels. Data represent mean + SEM of at least two independent experiments performed in duplicates and measured in triplicates; ${ }^{*} P<0.05, * * * P<0.001$ by Students $t$-test. 
permeabilized with $0.5 \%$ Triton X-100 (in PBS) for $5 \mathrm{~min}$ at RT and unspecific antigens were blocked with 4\% BSA (in PBS) for $1 \mathrm{~h}$ in a moist chamber. Then the slides were rinsed twice with PBS and the cells were stained with anti$\beta$-catenin antibody $\mathrm{ON}$ at $4^{\circ} \mathrm{C}$ followed by incubation with TRITC-conjugated anti-mouse as secondary antibody for $1 \mathrm{~h}$ at RT. Finally, cells were mounted with ProLong Gold antifade reagent with DAPI (Thermo Fisher Scientific) and analyzed by fluorescence microscopy (Olympus BX60, equipped with U-RLF-T). Serial pictures at 60-fold magnification were taken for each chamber and fluorescence images were acquired by using a Color View camera (Soft Imaging System) and the software CellSens (Olympus Life Science). Two independent experiments were performed. Used primary antibodies and corresponding secondary antibodies are shown in Supplementary Table S2.

\section{Real time quantitative PCR}

Total RNA was extracted using TRIzol reagent (Thermo Fisher Scientific). cDNA was synthesized using Superscript II and random hexamers (Invitrogen) or using the "RevertAidTM H Minus First Strand cDNA Synthesis Kit" (Thermo Fisher Scientific). Gene expression was quantified by SYBR Green-based qRTPCR assays on the "Step one plus system" or by the ABI Prism HT 7900 Detection System instrument and software (Applied Biosystems). Data were analyzed by using the GraphPad Prism software tool (San Diego, CA, USA) or by the standard curve method for relative quantification, respectively. The primers for amplification of target transcripts are shown in Supplementary Table S3.

All primer pairs were intron-flanking, except of the primers for $18 S$ and $M Y O D$. Amplification of $18 S$ rRNA or GAPDH mRNA served to normalize the amount of sample cDNA. Gene expression analyses summarize at least two independent experiments performed as duplicates and measured in triplicates. Graphs represent the mean value of all measurements plus SEM.

\section{CTNNB1 sequencing}

For CTNNB1 sequencing total DNA was extracted using a Maxwell ${ }^{\circledR}$ DNA Purification kit according to manufacturer's instructions (Promega). CTNNB1 exons were amplified via PCR using the primers listed in Supplementary Table S4. PCR products were precipitated by sodium acetate/ethanol. The resulting DNA pellet was dissolved in $10 \mu \mathrm{lddH_{2 }} 0$, of which $1 \mu \mathrm{l}$ was applied in the sequencing reaction using the BigDye Terminator v3.1 kit (Applied Biosystems). Sequencing products were purified by precipitating with sodium acetate/ethanol and dissolved in $15 \mu \mathrm{l}$ highly deionized formamide. Analysis was performed with an ABI3130 Genetic Analyzer (Applied Biosystems).

\section{Cell culture experiments}

The human ARMS cell lines RMS-13 (also known as Rh30) and Rh41 (also called Rh4) and the human ERMS cell line TE671 were obtained from ATCC (for cell lines see [37]). The ERMS and ARMS cell lines were cultured in RPMI, 10\% FCS (20\% FCS for Rh41), and 1\% penicillin/streptomycin.

For generation of stable LEF1 knockdown (LEF1 KD) cell lines, cells were transduced with lentiviral pGIPZ vector (GIPZ Lentiviral shRNAmir Library, Thermo Scientific Open Biosystems) containing LEF1 shRNA TGGAGTTGACATCTGATGG (mature sequence, Thermo Scientific) or empty vector using the packaging cell line HEK293T (ATCC, Rockville, USA). Stable cell lines were selected in medium with puromycin (puromycin dihydrochloride, Sigma-Aldrich Chemistry GmbH). The optimal concentration of puromycin was dependent on the cell line and was $0.5 \mu \mathrm{g} / \mathrm{ml}$ for RMS-13 and $2 \mu \mathrm{g} / \mathrm{ml}$ for Rh41 and TE671. Since the pGIPZ vector expresses GFP, control or shRNA expressing cells could also be visualized and monitored directly by fluorescence. All cell lines were continuously grown in puromycin-containing medium. Puromycin was withdrawn when cells were passaged for the last time before starting an experiment.

For gene expression analysis 300,000 (Rh41, RMS13, TE671) cells/well were seeded in 6-well-plates. After $24 \mathrm{~h}$, the cells were washed and harvested in TRIzol reagent.

For BrdU incorporation 6,000 cells/well were seeded in 96-well-plates. After $12 \mathrm{~h}$, the cells were incubated for additional $22 \mathrm{~h}$ with medium supplemented with $10 \mu \mathrm{M}$ BrdU. Cell proliferation after BrdU-pulsing was measured using a Cell Proliferation BrdU ELISA (Roche Diagnostics $\mathrm{GmbH}$ ). BrdU-incorporation is presented as the percentage of the incorporation measured in time-matched vehicle-treated control cells (that was set to $100 \%$ ).

For Annexin labeling 220,000 cells/well were seeded in 6-well-plates. After $12 \mathrm{~h}$, apoptosis was determined of cells stained with AnnexinV-APC (BD Biosciences) and 7-Amino-Actinomycin D (7-AAD, BD Biosciences). Stained cells were examined by flow cytometry on a LSRI flow cytometer (BD Biosciences), and data were analyzed with the FlowJo software (Tree Star, Inc.).

For cell migration assay 100,000 cells were seeded onto membrane-inserts (translucent track-etched polyethylene terephthalate (PET) membranes with $8 \mu \mathrm{m}$ pores, BD Biosciences), and incubated for $18 \mathrm{~h}$ in a 24-well-plate (BD Biosciences) in $500 \mu \mathrm{l}$ medium. Simultaneously, 100,000 cells/well were seeded in 24-well-plates in RPMI/10\% FCS or RPMI/20\% FCS, respectively to measure the cell proliferation. Afterwards the membrane-inserts were transferred into a new 24-wellplate and the cells were stained with $5 \mu \mathrm{M}$ calcein for $1 \mathrm{~h}$ 
at $37^{\circ} \mathrm{C}$. After washing with PBS and removing of cells on top of the membrane (cells which had not migrated), the cells at the bottom of the membrane were analyzed and counted on a microscope (Inverse microscope Carl Zeiss Jena $\mathrm{GmbH}$ ).

Invasion was measured by assessment of the RMS cell migration rate using an artificial basement membrane in a modified Boyden chamber as described [41]. In short the membrane consisted of a polycarbonate $(10 \mu \mathrm{m}$ pore diameter; Nucleopore) and was coated on ice with Matrigel (ECM gel) diluted 1:4 in serum-free RPMI. 100,000 RMS cells in $500 \mu \mathrm{l}$ medium were seeded into the upper well of the chamber, while the lower well was filled up to the top with RPMI. 10\% FCS served as a chemoattractant. Simultaneously, 100,000 cells/well were seeded in 24-well-plates in RPMI/10\% FCS or RPMI/20\% FCS to measure the cell proliferation. After $96 \mathrm{~h}$, the floating cells in the lower well were removed, pelleted by centrifugation, resolved in $1 \mathrm{ml}$ PBS and counted.

For TOP/FOP assay 5,000 cells/well were seeded in 96-well-plates. After $24 \mathrm{~h}$, the cells were incubated for additional $48 \mathrm{~h}$ with Wnt3a CM. Luciferase activity was measured using the Dual Luciferase Assay Kit (Promega) according to the manufacturer's protocol.

For immunofluorescence staining cells were seeded in 4-chamber culture slides (Thermo Fisher Scientific $\mathrm{GmbH})$ at a density of 40,000 cells/chamber. One day later cells were incubated with Wnt3a CM for $3 \mathrm{~h}$. Immunofluorescence staining was performed as described above.

The data shown summarize two independent experiments performed as triplicates (BrdU incorporation assay, migration assay for RMS-13) or as duplicates (apoptosis assay, migration and invasion assay, TOP/ FOP assay). Graphs represent the mean value of all measurements plus SEM.

\section{Preparation of Wnt3a conditioned medium}

Wnt3a conditioned media (Wnt3a CM) or respective control-conditioned media (control $\mathrm{CM}$ ) were obtained from murine L-cells (ATCC) stably transfected with Wnt3a expression plasmid or from non-transfected L-cells, respectively. Stable murine L-cells that overexpress Wnt3a were maintained in DMEM medium supplemented with $10 \% \mathrm{FCS}, 1 \%$ penicillin/streptomycin and $0.4 \mathrm{mg} / \mathrm{ml}$ G 418 (G 418 disulfate salt solution, Sigma-Aldrich Chemistry $\mathrm{GmbH}$ ). Wnt3a $\mathrm{CM}$ and control $\mathrm{CM}$ were prepared as described by a protocol provided by ATCC [42]. Briefly, the cells (for Wnt3a CM and control CM) were split $1: 10$ and cultivated with $10 \mathrm{ml}$ fresh medium without $\mathrm{G}$ 418 for 4 days. The medium was removed, clarified with a $0.2 \mu \mathrm{m}$ sterile filter (Omnilab-Krannich) and placed to $4^{\circ} \mathrm{C}$. Again, fresh medium $(10 \mathrm{ml})$ was added for another 3 days and processed as described. The first and second batches of conditioned media were pooled and stored at $4^{\circ} \mathrm{C}$.

\section{Transfection of RMS cells}

RMS cells were transfected using the NEON Transfection System (Thermo Fisher Scientific) according to the provided protocol. In brief, RMS cells were grown to $70 \%-90 \%$ confluence, harvested and counted. After washing, the cell pellet was resuspended in Resuspension Buffer R (included in the NEON Kit) with a final density of 4,000,000 cells $/ \mathrm{ml}$. 400,000 cells were mixed with $5 \mu \mathrm{g}$ siRNA or $6 \mu \mathrm{g}$ plasmid DNA in a final volume of $100 \mu \mathrm{l}$ Buffer R and subjected to electroporation under the following conditions: $1000 \mathrm{~V}, 2$ pulses, pulse time 30 msec. After $48 \mathrm{~h}$ the cells were collected by centrifugation at $750 \mathrm{rpm}$ for $5 \mathrm{~min}$ and used for subsequent experiments.

Canonical $\beta$-catenin-driven WNT signaling activity in RMS cell lines was measured after transfection with SuperTOPFlash (TOP) containing multiple TCF/LEFbinding sites or its negative control vector SuperFOPFlash (FOP) [43]. Renilla reporter plasmid was used for normalization. Wnt3a CM or control CM were added $24 \mathrm{~h}$ prior to harvesting. Co-transfection with $\mathrm{pCl}$-neo- $\beta$ catS33Y [44] served as positive control.

Knockdown of $\beta$-catenin expression in RMS cell lines was achieved by using a $\beta$-catenin-specific siRNA pool (Dharmacon ON-TARGETplus, siRNAs J-00348209 and J-003482-12) and scrambled siRNA (AllStars negative, Qiagen) was used as control siRNA.

\section{Western blot analysis}

Preparation of cell lysates and determination of protein concentrations were done as described previously [45]. Primary antibodies used to detect the individual target proteins and corresponding secondary antibodies are shown in Supplementary Table S2. All Western blots shown are representative for at least two independent experiments.

\section{CAM (chorioallantoic membrane) assay}

Fertilized White Leghorn chick eggs were incubated at $80 \%$ relative humidity and $37.8^{\circ} \mathrm{C}$. The eggs were windowed at day 3 and the window was sealed with adhesive tape (Leukosilk, BSN medical). At day 10 of chick development, two million RMS-13 cells/egg were resuspended in 50\% RPMI-medium and 50\% Matrigel and incubated for $30 \mathrm{~min}$ at $37^{\circ} \mathrm{C}, 5 \% \mathrm{CO}_{2}$ before applying them on the CAM. The tumors were dissected after 7 days (day 17 of chick development), fixed in $4 \%$ paraformaldehyde for $20 \mathrm{~min}$, washed twice in PBS and transferred into $10 \%$ sucrose for $3 \mathrm{~h}$ at $4^{\circ} \mathrm{C}$ and $30 \%$ sucrose $\mathrm{ON}$ at $4^{\circ} \mathrm{C}$. Tumors were then embedded in tissue freezing medium and cut with a cryotome into $14 \mu \mathrm{m}$ thick sections. The experiments were performed according to the guidelines of the European Parliament (2010/63/EU) and the council for the protection of 
animals in science ( $\$ 14$ TierSchVersV). Tumors and tumor cells were visualized by intravital GFP imaging and immunofluorescence.

\section{Statistical analyses}

If not otherwise indicated, statistical differences were analyzed using Mann-Whitney testing or Student's $t$-test. Data was considered significant when $P<0.05$.

\section{ACKNOWLEDGMENTS}

We are grateful to Berti Manshausen and Sonja Schwoch (Institute of Anatomy, University Medical Center Göttingen) and Lena Ries (Department of Haematology/ Medical Oncology, University Medical Center Göttingen) for technical assistance.

\section{CONFLICTS OF INTEREST}

No potential conflicts of interest were disclosed.

\section{GRANT SUPPORT}

The work of H.H. is supported by grants from the German Research Foundation DFG (HA 2197/9-1) and the German Cancer Aid DKH (111537). K.S-K. is supported by a Margarete-von-Wrangell fellowship.

\section{REFERENCES}

1. Dagher R, Helman L. Rhabdomyosarcoma: an overview. Oncologist. 1999; 4:34-44.

2. Ognjanovic S, Linabery AM, Charbonneau B, Ross JA. Trends in childhood rhabdomyosarcoma incidence and survival in the United States, 1975-2005. Cancer. 2009; $115: 4218-4226$.

3. Belyea B, Kephart JG, Blum J, Kirsch DG, Linardic CM. Embryonic signaling pathways and rhabdomyosarcoma: contributions to cancer development and opportunities for therapeutic targeting. Sarcoma. 2012; 2012:406239.

4. Williamson D, Missiaglia E, de Reynies A, Pierron G, Thuille B, Palenzuela G, Thway K, Orbach D, Lae M, Freneaux P, Pritchard-Jones K, Oberlin O, Shipley J, et al. Fusion gene-negative alveolar rhabdomyosarcoma is clinically and molecularly indistinguishable from embryonal rhabdomyosarcoma. J Clin Oncol. 2010; 28:2151-2158.

5. Merlino G, Helman LJ. Rhabdomyosarcoma--working out the pathways. Oncogene. 1999; 18:5340-5348.

6. Breneman JC, Lyden E, Pappo AS, Link MP, Anderson JR, Parham DM, Qualman SJ, Wharam MD, Donaldson SS, Maurer HM, Meyer WH, Baker KS, Paidas CN, et al. Prognostic factors and clinical outcomes in children and adolescents with metastatic rhabdomyosarcoma - a report from the Intergroup Rhabdomyosarcoma Study IV. J Clin Oncol. 2003; 21:78-84.

7. De Giovanni C, Landuzzi L, Nicoletti G, Lollini PL, Nanni P. Molecular and cellular biology of rhabdomyosarcoma. Future Oncol. 2009; 5:1449-1475.

8. Klaus A, Birchmeier W. Wnt signalling and its impact on development and cancer. Nat Rev Cancer. 2008; 8:387-398.

9. Hovanes K, Li TW, Munguia JE, Truong T, Milovanovic T, Lawrence Marsh J, Holcombe RF, Waterman ML. Betacatenin-sensitive isoforms of lymphoid enhancer factor-1 are selectively expressed in colon cancer. Nat Genet. 2001; 28:53-57.

10. Archbold HC, Yang YX, Chen L, Cadigan KM. How do they do Wnt they do?: regulation of transcription by the Wnt/beta-catenin pathway. Acta Physiol (Oxf). 2012; 204:74-109.

11. Arce L, Yokoyama NN, Waterman ML. Diversity of LEF/ TCF action in development and disease. Oncogene. 2006; 25:7492-7504.

12. Mao CD, Byers SW. Cell-context dependent TCF/LEF expression and function: alternative tales of repression, de-repression and activation potentials. Crit Rev Eukaryot Gene Expr. 2011; 21:207-236.

13. Grumolato L, Liu G, Haremaki T, Mungamuri SK, Mong P, Akiri G, Lopez-Bergami P, Arita A, Anouar Y, Mlodzik M, Ronai ZA, Brody J, Weinstein DC, et al. betaCatenin-independent activation of TCF1/LEF1 in human hematopoietic tumor cells through interaction with ATF2 transcription factors. PLoS Genet. 2013; 9:e1003603.

14. Xing S, Li F, Zeng Z, Zhao Y, Yu S, Shan Q, Li Y, Phillips FC, Maina PK, Qi HH, Liu C, Zhu J, Pope RM, et al. Tcf1 and Lef1 transcription factors establish CD8(+) T cell identity through intrinsic HDAC activity. Nat Immunol. 2016; 17:695-703.

15. Petropoulos K, Arseni N, Schessl C, Stadler CR, Rawat VP, Deshpande AJ, Heilmeier B, Hiddemann W, QuintanillaMartinez L, Bohlander SK, Feuring-Buske M, Buske C. A novel role for Lef-1, a central transcription mediator of Wnt signaling, in leukemogenesis. J Exp Med. 2008; 205:515-522.

16. Gutierrez A, Sanda T, Ma W, Zhang J, Grebliunaite R, Dahlberg S, Neuberg D, Protopopov A, Winter SS, Larson RS, Borowitz MJ, Silverman LB, Chin L, et al. Inactivation of LEF1 in T-cell acute lymphoblastic leukemia. Blood. 2010; 115:2845-2851.

17. Bouron-Dal Soglio D, Rougemont AL, Absi R, Giroux LM, Sanchez R, Barrette S, Fournet JC. Beta-catenin mutation does not seem to have an effect on the tumorigenesis of pediatric rhabdomyosarcomas. Pediatr Dev Pathol. 2009; 12:371-373.

18. Singh S, Vinson C, Gurley CM, Nolen GT, Beggs ML, Nagarajan R, Wagner EF, Parham DM, Peterson CA. Impaired Wnt signaling in embryonal rhabdomyosarcoma cells from p53/c-fos double mutant mice. Am J Pathol. 2010; 177:2055-2066. 
19. Annavarapu SR, Cialfi S, Dominici C, Kokai GK, Uccini S, Ceccarelli S, McDowell HP, Helliwell TR. Characterization of Wnt/beta-catenin signaling in rhabdomyosarcoma. Lab Invest. 2013.

20. Davicioni E, Anderson MJ, Finckenstein FG, Lynch JC, Qualman SJ, Shimada H, Schofield DE, Buckley JD, Meyer WH, Sorensen PH, Triche TJ. Molecular classification of rhabdomyosarcoma--genotypic and phenotypic determinants of diagnosis: a report from the Children's Oncology Group. Am J Pathol. 2009; 174:550-564.

21. Van de Wetering M, Castrop J, Korinek V, Clevers H. Extensive alternative splicing and dual promoter usage generate Tcf-1 protein isoforms with differential transcription control properties. Mol Cell Biol. 1996; 16:745-752.

22. Hughes TA, Brady HJ. Cross-talk between $\mathrm{pRb} / \mathrm{E} 2 \mathrm{~F}$ and Wnt/beta-catenin pathways: E2F1 induces axin2 leading to repression of Wnt signalling and to increased cell death. Exp Cell Res. 2005; 303:32-46.

23. Kimelman $\mathrm{D}, \mathrm{Xu}$ W. beta-catenin destruction complex: insights and questions from a structural perspective. Oncogene. 2006; 25:7482-7491.

24. Cadigan KM, Waterman ML. TCF/LEFs and Wnt signaling in the nucleus. Cold Spring Harb Perspect Biol. 2012; 4.

25. Shah M, Rennoll SA, Raup-Konsavage WM, Yochum GS. A dynamic exchange of TCF3 and TCF4 transcription factors controls MYC expression in colorectal cancer cells. Cell Cycle. 2015; 14:323-332.

26. Taulli R, Bersani F, Foglizzo V, Linari A, Vigna E, Ladanyi M, Tuschl T, Ponzetto C. The muscle-specific microRNA miR-206 blocks human rhabdomyosarcoma growth in xenotransplanted mice by promoting myogenic differentiation. J Clin Invest. 2009; 119:2366-2378.

27. Gebeshuber CA, Sladecek S, Grunert S. Beta-catenin/LEF-1 signalling in breast cancer--central players activated by a plethora of inputs. Cells Tissues Organs. 2007; 185:51-60.

28. Wu P, Shi KJ, An JJ, Ci YL, Li F, Hui KY, Yang Y, $\mathrm{Xu} \mathrm{CM}$. The LEF1/CYLD axis and cIAPs regulate RIP1 deubiquitination and trigger apoptosis in selenite-treated colorectal cancer cells. Cell Death Dis. 2014; 5:e1085.

29. Marampon F, Ciccarelli C, Zani BM. Down-regulation of c-Myc following MEK/ERK inhibition halts the expression of malignant phenotype in rhabdomyosarcoma and in non muscle-derived human tumors. Mol Cancer. 2006; 5:31.

30. Bernard S, Eilers M. Control of cell proliferation and growth by Myc proteins. Results Probl Cell Differ. 2006; 42:329-342.

31. Nanni P, Nicoletti G, Palladini A, Astolfi A, Rinella P, Croci S, Landuzzi L, Monduzzi G, Stivani V, Antognoli A, Murgo A, Ianzano M, De Giovanni $\mathrm{C}$, et al. Opposing control of rhabdomyosarcoma growth and differentiation by myogenin and interleukin 4. Mol Cancer Ther. 2009; 8:754-761.

32. Lollini PL, De Giovanni C, Landuzzi L, Nicoletti G, Scotlandi K, Nanni P. Reduced metastatic ability of in vitro differentiated human rhabdomyosarcoma cells. Invasion Metastasis. 1991; 11:116-124.
33. Harada A, Mallappa C, Okada S, Butler JT, Baker SP, Lawrence JB, Ohkawa Y, Imbalzano AN. Spatial re-organization of myogenic regulatory sequences temporally controls gene expression. Nucleic Acids Res. 2015; 43:2008-2021.

34. Andres V, Walsh K. Myogenin expression, cell cycle withdrawal, and phenotypic differentiation are temporally separable events that precede cell fusion upon myogenesis. J Cell Biol. 1996; 132:657-666.

35. Ross DA, Kadesch T. The notch intracellular domain can function as a coactivator for LEF-1. Mol Cell Biol. 2001; 21:7537-7544.

36. Seki M, Nishimura R, Yoshida K, Shimamura T, Shiraishi Y, Sato Y, Kato M, Chiba K, Tanaka H, Hoshino N, Nagae G, Shiozawa Y, Okuno Y, et al. Integrated genetic and epigenetic analysis defines novel molecular subgroups in rhabdomyosarcoma. Nat Commun. 2015; 6:7557.

37. Hinson AR, Jones R, Crose LE, Belyea BC, Barr FG, Linardic CM. Human rhabdomyosarcoma cell lines for rhabdomyosarcoma research: utility and pitfalls. Front Oncol. 2013; 3:183.

38. Chen EY, DeRan MT, Ignatius MS, Grandinetti KB, Clagg R, McCarthy KM, Lobbardi RM, Brockmann J, Keller C, $\mathrm{Wu}$ X, Langenau DM. Glycogen synthase kinase 3 inhibitors induce the canonical WNT/beta-catenin pathway to suppress growth and self-renewal in embryonal rhabdomyosarcoma. Proc Natl Acad Sci USA. 2014; 111:5349-5354.

39. Zeitler P, Pahnke J, Marx A. Expression of stromelysin-1 (MMP-3), gelatinase B (MMP-9), and plasminogen activator system during fetal calvarial development. Histopathology. 2004; 44:360-366.

40. Fedchenko N, Reifenrath J. Different approaches for interpretation and reporting of immunohistochemistry analysis results in the bone tissue - a review. Diagn Pathol. 2014; 9:221.

41. Hagemann T, Robinson SC, Schulz M, Trumper L, Balkwill FR, Binder C. Enhanced invasiveness of breast cancer cell lines upon co-cultivation with macrophages is due to TNF-alpha dependent up-regulation of matrix metalloproteases. Carcinogenesis. 2004; 25:1543-1549.

42. Willert K, Brown JD, Danenberg E, Duncan AW, Weissman IL, Reya T, Yates JR, 3rd and Nusse R. Wnt proteins are lipid-modified and can act as stem cell growth factors. Nature. 2003; 423:448-452.

43. Korinek V, Barker N, Morin PJ, van Wichen D, de Weger R, Kinzler KW, Vogelstein B, Clevers H. Constitutive transcriptional activation by a beta-catenin-Tcf complex in APC-/- colon carcinoma. Science. 1997; 275:1784-1787.

44. Morin PJ, Sparks AB, Korinek V, Barker N, Clevers H, Vogelstein B, Kinzler KW. Activation of beta-catenin-Tcf signaling in colon cancer by mutations in beta-catenin or APC. Science. 1997; 275:1787-1790.

45. Marklein D, Graab U, Naumann I, Yan T, Ridzewski R, Nitzki F, Rosenberger A, Dittmann K, Wienands J, Wojnowski L, Fulda S, Hahn H. PI3K inhibition enhances doxorubicin-induced apoptosis in sarcoma cells. PLoS ONE. 2012; 7:e52898. 